\title{
Redes pessoais e desempenho escolar no ensino básico: um estudo sobre os alunos concluintes do Ensino Médio da Escola Estadual Santos Dumont, Parnamirim no Rio Grande do Norte, Brasil'
}

\author{
Personal networks and school performance in elementary education: a study on the final \\ students of the Santos Dumont State School, Parnamirim in Rio Grande do Norte, Brazil ${ }^{2}$ \\ Redes personales y desempeño escolar en la enseñanza básica: un estudio sobre los \\ alumnos concluyentes de la Enseñanza Media de la Escuela Estadual Santos Dumont, \\ Parnamirim en Rio Grande do Norte, Brasil ${ }^{3}$
}

Bruno Lopes-da Silva

Universidade Federal do Rio Grande do Norte

Programa de Pós-Graduação em Geografia

Natal, Brasil

blsilva1986@bol.com.br

iD $h t$ tps://orcid.org/0000-0002-8464-078X

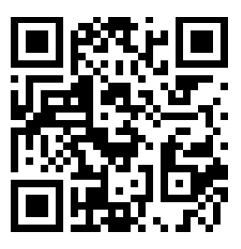

Moisés Alberto Calle-Aguirre Universidade Federal do Rio Grande do Norte Programa de Pós-Graduação em Demografia

Natal, Brasil calle@ccet.ufrn.br

iD https://orcid.org/0000-0002-7347-478X

Valério Bezerra-de Lima

Governo do Estado do Rio Grande do Norte Escola Estadual lelmo Marinho lelmo Marinho, Brasil valeriogeof@hotmail.com https://orcid.org/0000-0002-2451-5805

Recibido • Received • Recebido: 20 / 02 / 2018

Corregido • Revised • Revisado: 19 / 06 / 2019

Aceptado • Accepted • Aprovado: 29/ 10 / 2019

\footnotetext{
${ }^{1}$ Este artigo foi elaborado com base na dissertação de mestrado intitulada "O desempenho escolar na perspectiva das Redes Sociais/Pessoais: um estudo sobre as Escolas Estaduais Santos Dumont e Ana Júlia de Carvalho Mousinho", realizada com apoio da CAPES/OBEDUC, no âmbito do Projeto Habitus de Estudar: construtor de uma nova realidade da educação básica da Região Metropolitana de Natal.

${ }^{2}$ This article was elaborated based on the master dissertation titled "School performance from the perspective of Social / Personal Networks: a study on the Santos Dumont State Schools and Ana Júlia de Carvalho Mousinho", carried out with the support of CAPES / OBEDUC, in the ambit of the Project Habitus de Estudar: constructor of a new reality of the basic education of the Metropolitan Region of Natal.

${ }^{3}$ Este artículo fue elaborado con base en la disertación de maestría titulada "El desempeño escolar en la perspectiva de las Redes Sociales / Personal: Un estudio sobre las Escuelas Estaduales Santos Dumont y Ana Júlia de Carvalho Mousinho", realizada con apoyo de CAPES / OBEDUC, en el marco del Proyecto Habitus de Estudiar: constructor de una nueva realidad de la educación básica de la Región Metropolitana de Natal.
} 
doi: http://doi.org/10.15359/ree.24-1.7

URL: http://www.una.ac.cr/educare

CORREO: educare@una.cr

Resumo: As redes pessoais para modelar as relações entre um grupo de indivíduos têm sido bastante utilizadas nas ciências sociais, especialmente na Sociologia. Apesar disso, esse tipo de abordagem abrange outras áreas do saber científico. No caso da educação, por exemplo, o uso das redes pessoais pode servir de subsídio para o mapeamento do campo relacional que envolve um determinado indivíduo, considerando os seus diferentes espaços educativos. Nesse sentido, pressupõe-se que o uso das redes pessoais pode servir como ferramenta metodológica para a identificação dos campos relacionais que permeiam o desempenho escolar de um aluno durante a sua escolarização. Diante disso, o objetivo desse trabalho é analisar a relação entre redes pessoais e desempenho escolar com alunos da Terceira Série do Ensino Médio de 2015 da Escola Estadual Santos Dumont, localizada no município de Parnamirim no Rio Grande do Norte, Brasil. Para alcançar esse objetivo, a metodologia adotada foi constituída por cinco procedimentos específicos: 1) Uma revisão de literatura sobre redes pessoais e desempenho escolar, com ênfase nos conceitos de densidade (grau de conectividade da rede) e número de cliques (agrupamento de nós, a partir de três ou mais atores que mantêm ligações entre si.); 2) Aplicação de questionário para coleta dos dados de redes pessoais, por meio do qual os alunos mencionaram o nome de 45 pessoas que eles conheciam; o grau de proximidade e o tipo de relação que els tinham com cada uma das 45 pessoas mencionadas; 3 ) Cálculo dos valores de densidade e número de cliques (indicadores de redes); 4) Obtenção das notas de Português e Matemática dos alunos; e 5) Aplicação do modelo de regressão logística para identificar as prováveis relações entre a rede pessoal e o desempenho escolar de cada aluno investigado. Os resultados obtidos evidenciaram que alunos com redes muito densas tendem a tirar notas baixas em Português, enquanto que os alunos com redes que têm muitos cliques apresentam uma certa tendência a tirarem notas baixas em Matemática.

Palavras-Chave: Desempenho escolar; educação; redes pessoais.

Abstract: Personal networks for modeling relationships among a group of individuals have been widely used in the social sciences, especially in Sociology. Nevertheless, this type of approach covers other areas of scientific knowledge. In the case of education, for example, the use of personal networks can serve as a basis for the mapping of the relational field that involves a particular individual, considering their different educational spaces. In this sense, it is assumed that the use of personal networks can serve as a methodological tool for the identification of the relational fields that permeate a student's school performance during their schooling. Therefore, the objective of this work is to analyze the relationship between personal networks and school performance with students of the High School Series of the Santos Dumont State School, located in the municipality of Parnamirim, Rio Grande do Norte, Brazil. In order to reach this goal, the methodology adopted consisted of five specific procedures: 1) A literature review on personal networks and school performance, with emphasis on the concepts of density (degree of network connectivity) and the number of clicks (clustering of nodes, from three or more actors who maintain links between them.); 2) Application of a questionnaire to collect the data of personal networks, through which the students mentioned the name of 45 people they knew; the degree of proximity and the type of relationship they had with each of the 45 people mentioned; 3) Calculation of density values and number of clicks (network indicators); 4) Obtaining the notes of Portuguese and Mathematics of the students; and 5) Application of the logistic regression model to identify the likely relationships between the personal network and the school performance of each student investigated. The results obtained showed that students with very dense networks tend to take low grades in Portuguese, while students with networks that have many clicks show a certain tendency to take low grades in Mathematics.

Keywords: Education; personal networks; school performance. 


\begin{abstract}
Resumen: Las redes personales para modelar las relaciones entre un grupo de individuos han sido muy utilizadas en las ciencias sociales, especialmente en la sociología. Sin embargo, este tipo de enfoque abarca otras áreas del conocimiento científico. En el caso de la educación, por ejemplo, el uso de estas redes puede servir de subsidio para el mapeo del campo relacional que involucra a un determinado individuo, considerando sus diferentes espacios educativos. En ese sentido, se presupone que su uso puede servir como herramienta metodológica para la identificación de los campos relacionales que permean el desempeño escolar de estudiantes durante su escolarización. El objetivo de este trabajo es analizar la relación entre redes personales y desempeño escolar con alumnado de la Tercera Serie de la Enseñanza Media de 2015 de la Escuela Estadual Santos Dumont, ubicada en el municipio de Parnamirim en Rio Grande do Norte, Brasil. Para alcanzar este objetivo, la metodología adoptada fue constituida por cinco procedimientos específicos: 1) Una revisión de bibliografía sobre redes personales y desempeño escolar, con énfasis en los conceptos de densidad (grado de conectividad de la red) y número de clics (agrupación de nodos, a partir de tres o más actores que mantienen vínculos entre sí). 2) Aplicación de cuestionario para la recolección de los datos de redes personales, por medio del cual el alumnado mencionó el nombre de 45 personas que conocía; el grado de proximidad y el tipo de relación que tenía con cada una de estas. 3) Cálculo de los valores de densidad y número de clics (indicadores de redes). 4) Colección de notas de estudiantes de portugués y matemática. 5) Aplicación del modelo de regresión logística para identificar las probables relaciones entre la red personal y el desempeño escolar de cada estudiante participante. Los resultados mostraron que estudiantes con redes muy densas tienden a obtener malas calificaciones en portugués; mientras que estudiantes con redes que tienen muchos clics tienen una tendencia a tener bajas calificaciones en matemáticas.
\end{abstract}

Palabras claves: Educación; desempeño escolar; redes personales.

\title{
Introdução
}

A análise de redes pessoais, enquanto método de pesquisa científica, está amparada tradicionalmente nos paradigmas de natureza sociológica -Holismo e Individualismo- os quais criaram as bases necessárias para o desenvolvimento e a aplicabilidade do conceito de redes. Com o passar o tempo, as metodologias de análises de redes começaram a ser desenvolvidas, possibilitando atualmente calcular e obter estimativas das características topológicas de uma estrutura reticular por meio de determinados indicadores.

Esse arcabouço analítico pertencente à análise de redes fez com que essa abordagem extrapolasse o campo da Sociologia e passasse a atuar em outras áreas do saber. Na educação, por exemplo, a análise de redes começa a ser utilizada como método de pesquisa, o que pode proporcionar para os próximos anos o desenvolvimento de diversos estudos sobre a estrutura relacional do processo educativo.

Dessa forma, por meio da utilização da abordagem relacional será possível a realização do mapeamento das redes pessoais formadas em diferentes espaços educativos, tais como as redes de âmbito familiar, as redes constituídas no ambiente escolar, bem como as redes estabelecidas pelas relações de vizinhança. 
doi: http://doi.org/10.15359/ree.24-1.7

URL: http://www.una.ac.cr/educare

CORREO: educare@una.cr

Partindo desses pressupostos, a abordagem teórico-metodológica das redes pessoais pode ser utilizada para o desenvolvimento de investigações sobre o desempenho escolar de alunos, independentemente do nível de ensino. Pois, ao se adotar essa estratégia, busca-se identificar de que forma as relações pessoais influenciam no rendimento dos estudos, mais precisamente no que diz respeito ao aproveitamento de disciplinas curriculares.

Diante disso, definiu-se como recorte empírico para o desenvolvimento dessa análise os alunos da 3a Série do Ensino Médio (do ano de 2015) da Escola Estadual Santos Dumont. Essa escola está localizada no município de Parnamirim, Rio Grande do Norte, a qual se encontra sob jurisdição do governo estadual.

Tem-se como objetivo analisar a relação entre as redes pessoais e o desempenho escolar dos alunos. Para alcançar esse objetivo, a discussão foi dividida em quatro seções: na primeira, discute-se o método de abordagem relacional, destacando os seus paradigmas, conceitos e indicadores; na segunda, aborda-se a relação das redes pessoais no contexto dos espaços educativos; na terceira, faz-se a apresentação dos procedimentos metodológicos utilizados; e na quarta, discute-se a relação entre redes pessoais e desempenho escolar.

\section{O método de abordagem relacional: paradigmas, conceitos e indicadores}

O desenvolvimento de estudos no campo sociológico, na maioria dos casos, baseia-se em uma perspectiva estruturalista para a fundamentação teórica e conceitual de seus objetos de estudo. No caso das análises sobre redes pessoais é imprescindível a adoção dessa perspectiva analítica, tendo em vista se entender as relações que ocorrem entre os nós dessa rede, ou seja, considerar as interações entre as partes (o individual-os nós) para compreender o todo (o coletivo-a rede) (Watts, 2009).

Essa estrutura que caracteriza as relações sociais possui também uma organização em forma de sistema, uma vez que, as modificações ocorridas em uma das partes desse sistema de relações se tornam capazes de alterar o comportamento da estrutura como um todo (Meksenas, 2002). Sendo assim, ao considerar a sociedade enquanto um sistema, uma de suas partes só é compreendida quando relacionada ao todo.

Esse aspecto coloca em evidência os paradigmas de análise das estruturas sociais, conhecidos cientificamente como Individualismo, ou Atomismo, e Holismo. O Individualismo/ Atomismo considera as relações pessoais desenvolvidas pelo indivíduo sobre o funcionamento da estrutura. Nessa perspectiva, o Individualismo/Atomismo apresenta uma visão de mundo de caráter liberal, na qual as ações individuais se desenvolvem independentemente da estrutura existente, em que as pessoas acabam agindo de acordo com os seus desejos e suas necessidades (Berten, 2007). 
Diferentemente do Individualismo/Atomismo, a perspectiva holística pressupõe que a estrutura condiciona a ação individual. Isto é, o funcionamento da sociedade como um todo não pode ser apreendido ou explicado somente com base nas ações e nos comportamentos individuais. Na visão de Berten (2007), o Holismo é um paradigma importante porque "permite dizer que a sociedade precede a individualidade, que ela é uma precondição da individualidade" (p. 18). De acordo com o pensamento desse autor, é praticamente impossível o indivíduo desenvolver suas ações e suas atitudes de forma isolada, sem manter um quadro de relações com outras pessoas, porque é esse campo relacional que torna o homem um ser social por excelência.

Nesse sentido, ao agregar esses dois níveis de análise, criam-se os pré-requisitos para o desenvolvimento de uma abordagem do tipo relacional, caracterizada pela existência de um diálogo entre ação individual e coletiva, na qual pode haver uma troca de recursos entre os elementos componentes dessa estrutura (Luhmann, 1995).

De acordo com Levi-Strauss (1980), o entendimento dessa estrutura social não se baseia, necessariamente, em uma realidade empírica, mas sim em uma perspectiva de análise que leva em consideração a representação do campo relacional da realidade através de modelos. Nesses modelos de representação estruturalista da sociedade, a realidade passa a ser analisada enquanto um conjunto fragmentado e articulado de partes, cujos diferentes níveis se encontram em processo de interação.

Dessa maneira, ao se adotar a rede como modelo de representação da interação entre pessoas, define-se como elementos constitutivos dessa modelagem social da realidade as seguintes partes: os nós (são os atores que se encontram em torno de um objetivo comum); os vínculos (laços que existem entre dois ou mais nós); e o fluxo (direção do vínculo). Esses elementos de representação, além de possuírem conceituação própria no contexto da rede, são importantes pelo fato de demonstrarem a maneira pela qual o comportamento individual se relaciona com coletivo (Velázquez \& Aguilar, 2005).

Por esse motivo, parte-se do pressuposto de que a articulação entre estruturalismo e interacionsimo proporcionou os fundamentos teóricos e metodológicos necessários para a construção e fundamentação do conceito de redes. Nesse viés, a estrutura afeta o sujeito e o sujeito afeta a estrutura (Degenne \& Forsé, 1999; Soares, 2002).

Foi com base nesses pressupostos paradigmáticos e metodológicos, que o conceito de rede foi construído. Este passou a ser interpretado de diferentes maneiras pelos diversos estudiosos responsáveis por realizar pesquisas sobre o assunto, tal como pode ser constatado nessas definições: conjunto de atores, entre os quais existem vínculos (Hanneman, 2001); conjunto de nós interconectados (Castells, 1999); conjunto de atores (nós da rede) e suas ligações (Tomaél \& Marteleto, 2013); grupo de indivíduos que, em forma agrupada ou individual, se relacionam com outros com um fim específico (Velázquez \& Aguilar, 2005); conjunto de atores amarrados ou 
doi: http://doi.org/10.15359/ree.24-1.7

URL: http://www.una.ac.cr/educare

CORREO: educare@una.cr

ligados entre si (Wasserman \& Faust, 1996); estrutura de relações e comportamentos individuais (Degenne \& Forsé, 1999); e conjunto de objetos conectados entre si de certo modo (Watts, 2009).

Uma das formas de operacionalizar esse conceito é através da utilização de indicadores ou métricas, que proporcionam estimativas das propriedades topológicas da rede. Dentre os indicadores mais usados, destacam-se a densidade e o número de cliques (Velázquez \& Aguilar, 2005; Watts, 2009).

Em relação à densidade, cabe dizer que ela se constitui em um indicador que analisa o grau de conectividade da rede, sendo expressa em porcentagem, a partir do quociente entre o número de relações existentes e as relações possíveis. Esse indicador permite também analisar as respectivas posições dos atores ativos na rede, e os seus padrões de trocas de informação e contato social (Velázquez \& Aguiilar, 2005).

Segundo Bortoni-Ricardo (2005), quando as redes apresentam um alto grau de Densidade, seus membros atingem grande consenso normativo e exercem consistente pressão informal uns sobre os outros visando à conformação às normas consensuais. Por outro lado, quando a rede apresenta tessitura frouxa, há maior probabilidade de ocorrer uma variação nas normas.

Em termos práticos, esse indicador pode ser usado para modelar grupos de pessoas que se conhecem entre si, nos quais se estabelece o compartilhamento de experiências de indivíduos com atitudes e comportamentos parecidos (Watts, 2009).

No caso do número de cliques, trata-se de uma medida caracteriza por um agrupamento de nós, em que três ou mais atores escolhem a todos do subgrupo, como pares em suas ligações, por meio de uma relação recíproca (de Azevedo \& Rodrigues, 2010). Esses cliques ao se formarem podem dar origem a rede de duas tipologias: justaposição e sobreposição. A rede por justaposição de cliques forma-se quando dois cliques são conectadas por um único vértice, ao passo que as de sobreposição caracterizam-se por apresentar dois ou mais vértices (Rosa, Fadigas, Andrade \& Pereira, 2012).

Com base na compreensão desses indicadores ou métricas, torna-se possível desenvolver uma análise consistente sobre as topologias e propriedades de uma rede social. Apesar de possuírem um caráter quantitativo, esses indicadores podem ser utilizados para o estudo de redes de diferentes naturezas, como por exemplo, no campo educacional, em pesquisas que abordam os mecanismos de interação e de troca de conhecimentos de um determinado grupo de pessoas, em seus diferentes espaços educativos. Por esse motivo, a análise de redes se constitui em um método de investigação científica de extrema relevância, dada a sua abrangência em termos de aplicabilidade, e a sua riqueza paradigmática, teórica e metodológica. 


\section{As redes pessoais no contexto dos espaços educativos}

Pensar os espaços educativos numa perspectiva relacional é o mesmo que considerálos enquanto ambientes privilegiados e propícios para o processo de inter-relação humana. Desse modo, a educação, analisada a partir dessa ótica, insere-se no contexto de um sistema de intercâmbio pessoal por onde se dá a socialização e a transmissão cultural de conhecimento entre os atores que fazem parte dessa teia (Soares, 1995). A existência desse espaço relacional, consequentemente, poderá trazer grande impacto no processo de difusão, compartilhamento e construção de conhecimento, uma vez que a educação enquanto processo social poderá ser comparada a um "autêntico ecossistema comunicacional" (Soares, 1995, p. 15), fruto dos diversos tipos de interações estabelecidas.

Esses espaços educativos podem ser representados de diferentes formas, podendo ser estruturados no âmbito da família, da escola, ou das relações de vizinhança desenvolvidas pelas pessoas em suas relações cotidianas (Gadotti, 2005). Ao estabelecer relações nesses espaços, o indivíduo tende a construir uma rede de contatos pessoais, por meio da qual se dá o seu processo de inculcação de valores, ideias e conhecimentos historicamente produzidos.

Por esse motivo, há a necessidade de se analisar o papel das redes pessoais formadas no âmbito da família, da escola e das relações de vizinhança, tendo em vista identificar as especificidades de suas estruturas relacionais e as influências exercidas pelos diferentes atores (Bourdieu, 2001).

Considerando a família como uma das principais instituições sociais da humanidade, parte-se do pressuposto de que a influência exercida pelos pais nas suas relações cotidianas, tem se constituído em um elemento de grande importância para a transmissão intergeracional de conhecimentos. Esse processo de transmissão no contexto de uma família, consiste nos legados, rituais e tradições que são repassados de uma geração para outra, por meio de uma rede pessoal baseada nas relações de parentesco. É a partir dessa ligação intergeracional de atores historicamente diferentes, que as tradições familiares são legitimadas ao longo do tempo, uma vez que, a interdependência hereditária desses indivíduos tem sido responsável pela preservação dos valores culturais das gerações passadas (Lisboa, Féres-Carneiro e Jablonski, 2007).

Assim, desde o nascimento, o indivíduo está submetido a uma rede de influência contínua e socialmente construída, em que na maioria das vezes os familiares se destacam como atores principais. Essa teia de relações sociais, por sua vez, reúne pessoas de gerações diferentes, que nasceram e cresceram em tempos distintos, as quais, em função disso, percebem e sentem os acontecimentos de maneiras distintas pelo fato de possuírem posições diferentes na rede pessoal de relações de parentesco (Borges e Magalhães, 2011). 
doi: http://doi.org/10.15359/ree.24-1.7

URL: http://www.una.ac.cr/educare

CORREO: educare@una.cr

Além da família, uma outra esfera social que promove o processo educativo é a escola, a qual tem como responsabilidade a transmissão e a socialização de conhecimento de forma institucionalizada. No âmbito dessa instituição coexistem uma série de atores sociais que se relacionam, interagem e trocam conhecimentos-representados por professores, alunos e funcionários da escola (Carvalho, 2013).

Apesar de muitas vezes estarem em grupos sociais distintos, esses atores do ponto de vista institucional estão compartilhando as normas que são impostas pela escola, fazendo com que os seus comportamentos sejam orientados de acordo com as expectativas da instituição. Assim, analisando a escola enquanto um espaço social onde há o relacionamento de indivíduos com diferentes papéis, a difusão e o compartilhamento das normas e dos costumes da cultura escolar entre os diferentes atores torna esta instituição uma grande rede de sociabilidade, um espaço de criação coletiva (Carvalho, 2013).

Em meio a essa teia de relações, os gestores da instituição tendem a influenciar o comportamento do professor, e vice-versa. Do mesmo modo, o comportamento do professor poderá influenciar o dos alunos, ao passo que o comportamento dos alunos poderá ter grande impacto sobre as decisões e direcionamentos do professor. Por esse motivo, a escola deve ser considerada um reflexo da sociedade, pois além de transmitir o conhecimento historicamente acumulado entre gerações, nela se reproduzem muitas das relações que acontecem em outras esferas da sociedade, como por exemplo, a formação de grupos e a existência de atores influentes (Sprinthall \& Sprinthall, 1997).

Da mesma forma que a família e a escola, o processo educativo pode se desenvolver também no contexto das relações de vizinhança, estabelecidas na comunidade onde o indivíduo mora. Essa comunidade pode proporcionar relações pautadas na convivência, na proximidade, no compartilhamento de bens e na contiguidade populacional, o que pode determinar o contato mútuo entre seus habitantes. Esse relacionamento pessoal via comunidade poderá criar as condições necessárias para manter a unidade de um grupo de indivíduos, em termos de coesão e de reciprocidade (Tönnies, 1887).

Essa condição é, antes de tudo, um fenômeno de cunho moral, que cria laços, ordens e normas de conduta que proporcionam a integração social dos indivíduos no contexto comunitário. Dessa maneira, o grupo adquire mais unidade e as ações de cada ator em sua realidade local passam a ser permeadas pela interdependência e pelo fluxo de informação que se estabelece com outros atores (Tönnies, 1887).

Trata-se de um processo onde a pessoa internaliza conceitos, significados e valores, como também transmite os conceitos, valores e significados que carrega consigo (Lemos, 2010-2011). 
Essas relações são importantes para se compreender a reprodução dos padrões sociais cultivados entre os indivíduos. Nessa reprodução, a vontade de um ator interfere e se imbrica ante a vontade de outro, estabelecendo-se uma relação de interação que pode afetar a conquista de algumas metas pessoais (Lemos, 2010-2011). Supõe-se que a rede pessoal formada a partir de diferentes espaços educativos exerce um campo de influência sobre o indivíduo, que pode determinar o seu desenvolvimento e progresso pessoal nos mais variados segmentos da sociedade.

Vale destacar que essa rede pessoal formada em diferentes espaços educativos pode ser utilizada, por exemplo, para o desenvolvimento de pesquisas sobre o campo relacional do desempenho escolar. Mas, para comprovar ou não essas pressuposições, há a necessidade de se definir uma metodologia de análise que possa articular as diferentes variáveis que são utilizadas.

\section{Proocedimentos metodológicos}

Além da realização de uma revisão bibliográfica sobre redes pessoais e desempenho escolar baseada em uma pesquisa junto a sociolólogos e demais estudiosos no assunto, os procedimentos metodológicos incluíram também o cálculo dos indicadores de redes, cujos resultados foram associados às notas dos alunos.

A revisão de literatura foi feita com base em dois eixos teórico-conceituais específicos: redes pessoais e desempenho escolar. No eixo de redes pessoais foram trabalhadas caracteríticas analíticas como os paradigmas (estruturalismo/atomismo), os conceitos de nós e vínculos, e os indicadores de análise estrutural de rede (densidade e número de cliques). No eixo de desempenho escolar foi abordada a influência da rede pessoal do aluno sobre o seu fluxo escolar do aluno (aprovação, reprovação e abandono).

Para coletar os dados de redes pessoais foi utilizado um questionário, o qual foi respondido pelos alunos da $3^{\text {a }}$ série do Ensino Médio da Escola Estadual Santos Dumont, na qual 67 alunos foram pesquisados. A escolha desses alunos levou em considerção o ciclo educacional em que eles estavam, ou seja, foram pesquisados os alunos que cursavam a 3 a Série do Ensino Médio alunos concluintes.

Nesse questionário de caráter relacional, os alunos mencionaram o nome de 45 pessoas que eles conheciam; o grau de proximidade (definido com base em um escala de afinidade que define a intensidade da relação - Distante (1); pouco próximo (2); próximo (3); e muito próximo (4)) e o tipo de relação (pai, mãe, irmão, primo, amigos, etc) do aluno com cada uma das 45 pessoas mencionadas) (Hanneman, 2001; Wasserman \& Faust, 1996).

A partir dos dados coletados, foram calculados dois indicadores de redes: densidade e número de cliques. O cálculo desses inidicadores e os gráficos de redes foram desenvolvidos com apoio de dois softwares: UCINET e NETDRAW. 
doi: http://doi.org/10.15359/ree.24-1.7

URL: http://www.una.ac.cr/educare

CORREO: educare@una.cr

Já as informações de desempenho escolar, basearam-se nas notas de dois componentes curriculares, Língua Portuguesa e Matemática, por se tratarem de duas disciplinas usadas como referência no processo de avaliação da qualidade do Ensino Básico. Foram consultadas as fichas de desempenho dos alunos selecionados na amostra, onde procurou-se identificar o rendimento desses discentes, nas respectivas disciplinas, mais precisamente, as suas médias finais anuais.

Essas informações de rendimento escolar foram associadas posteriormente aos valores de densidade e número de cliques de cada aluno, por meio de um modelo de regressão logística. Esse modelo teve como variáveis respostas as notas de Português e de Matemática, e como variáveis explicativas, os valores de densidade e número de cliques.

No caso do banco de dados da escola, a regressão logística foi desenvolvida da seguinte forma: As notas de Português e de Matemática são as variáveis dependentes, de caráter categórico. O processo de dicotomização levou em consideração o seguinte ponto de corte: Notas maiores ou iguais a 7,0 são categorizadas como "Sucesso" $(\mathrm{N} \geq 7,0=$ Sucesso $=1)$; e notas menores que 7,0 serão categorizadas como "Insucesso" $(\mathrm{N}<7,0=$ Insucesso $=0)$. Nesse caso foram desenvolvidos dois modelos de regressão: um modelo tendo como variável resposta as notas de Português (Sucesso/Insucesso) e como variáveis explicativas densidade, e número de cliques; e o outro tendo como variável dependente Matemática e como variáveis independentes densidade e número de cliques.

Todos esses procedimentos usados, visaram sobretudo, identificar as relações entre redes pessoais e desempenho escolar dos alunos investigados. Por isso, é importante entender teoricamente como se estabelece essa ligação entre esses dois campos de análise (Redes pessoais e desempenho escolar).

\section{Redes pessoais e desempenho escolar}

O desempenho escolar se constitui em um dos elementos que compõem a análise do processo educativo, principalmente no âmbito da educação formal na qual são realizadas avaliações acerca do aproveitamento e da frequência do aluno, podendo este ser considerado aprovado, reprovado ou afastado por abandono. Na maioria dos casos, essas informações de desempenho são obtidas por meio de indicadores, tais como as taxas de aprovação, reprovação, evasão e abandono (Rigotti e Cerqueira, 2004).

Contudo, uma ressalva deve ser feita acerca do significado do desempenho escolar no contexto do processo educativo. O desempenho escolar em uma perspectiva ampla deve ser analisado não só com base nos indicadores, mas é importante que esses indicadores sejam associados aos fatores que compõem o campo relacional do indivíduo (Riani, 2004). Isso 
significa dizer que os resultados apresentados pelos indicadores educacionais têm grandes possibilidades de serem influenciados por uma rede de relações sociais estabelecida pelos indivíduos em suas redes pessoais.

Dessa maneira, para se estabelecer uma relação entre redes pessoais e desempenho escolar, uma das estratégias metodológicas a ser adotada é a articulação de indicadores numa perspectiva multivariada. Para exemplificar essa articulação, definiu-se como estudo de caso os alunos da 3a Série do Ensino Médio da Escola Estadual Santos Dumont, localizada no município de Parnamirim, Rio Grande do Norte. Tratavam-se de alunos que estavam concluindo o Ensino Médio no ano de 2015.

Definiu-se como indicadores de desempenho escolar as médias finais de Português e de Matemática de cada um desses alunos. E como indicadores de redes pessoais, as medidas de densidade e número de cliques.

A partir da interpretação dos resultados, contatou-se que os alunos com redes de densidade moderada $(0,4 \%$ a $0,6 \%)$ apresentam menor desempenho em Português. Uma das justificativas que pode explicar o fato da densidade moderada interferir negativamente no sucesso do aluno em Português diz respeito a natureza dos laços estabelecidos. A rede pessoal do aluno pode apresentar alta densidade, mas para que esse aspecto influencie positivamente sobre o seu aprendizado é necessário que os laços estabelecidos com os outros atores estejam promovendo a obtenção de informações que potencializem o seu aprendizado (MartinezOtero, 2012). Nesse sentido, é conveniente salientar que em uma rede com alta ou moderada densidade podem existir relações que não contribuam positivamente ao processo educacional do aluno na escola.

Nesse sentido, é preciso ir além dos valores em si de densidade, é preciso identificar qualitativamente o conteúdo e a natureza de cala ligação estabelecida pelo aluno, ou seja, que tipo de informação/influência ele está recebendo ao estabelecer contato com determinada pessoa. Por exemplo, em seu ciclo de amizades, há amigos que gostam de estudar Português, e que por consequência disso acabam influenciando positivamente no aprendizado dessa disciplina? Ou pode acontecer o contrário, amigos que não têm interesse por essa disciplina e por isso podem acabar influênciando negativamente no demsepnho do aluno. Além do mais, um outro ponto a se destacar é a natureza do laço, pois a pessoa tende a ser mais influenciado por alguém com a qual tem um vínculo forte de amizade.

Para podermos melhor exemplificar esse cenário interacional em relação à questão da densidade, ao visualizar na Figura 1 a representação do sociograma de um dado aluno oriundo da Escola Estadual Santos Dumont, em que, nesse caso, o discente foi o que apresentou a mais alta densidade $(72,2 \%$ ou 0,772$)$ no âmbito dos demais alunos analisados, podemos, justamente, pensar em questões presentes nessa configuração relacional para investigar seu sucesso ou insucesso nas disciplinas em questão 
doi: http://doi.org/10.15359/ree.24-1.7

URL: http://www.una.ac.cr/educare

CORREO: educare@una.cr

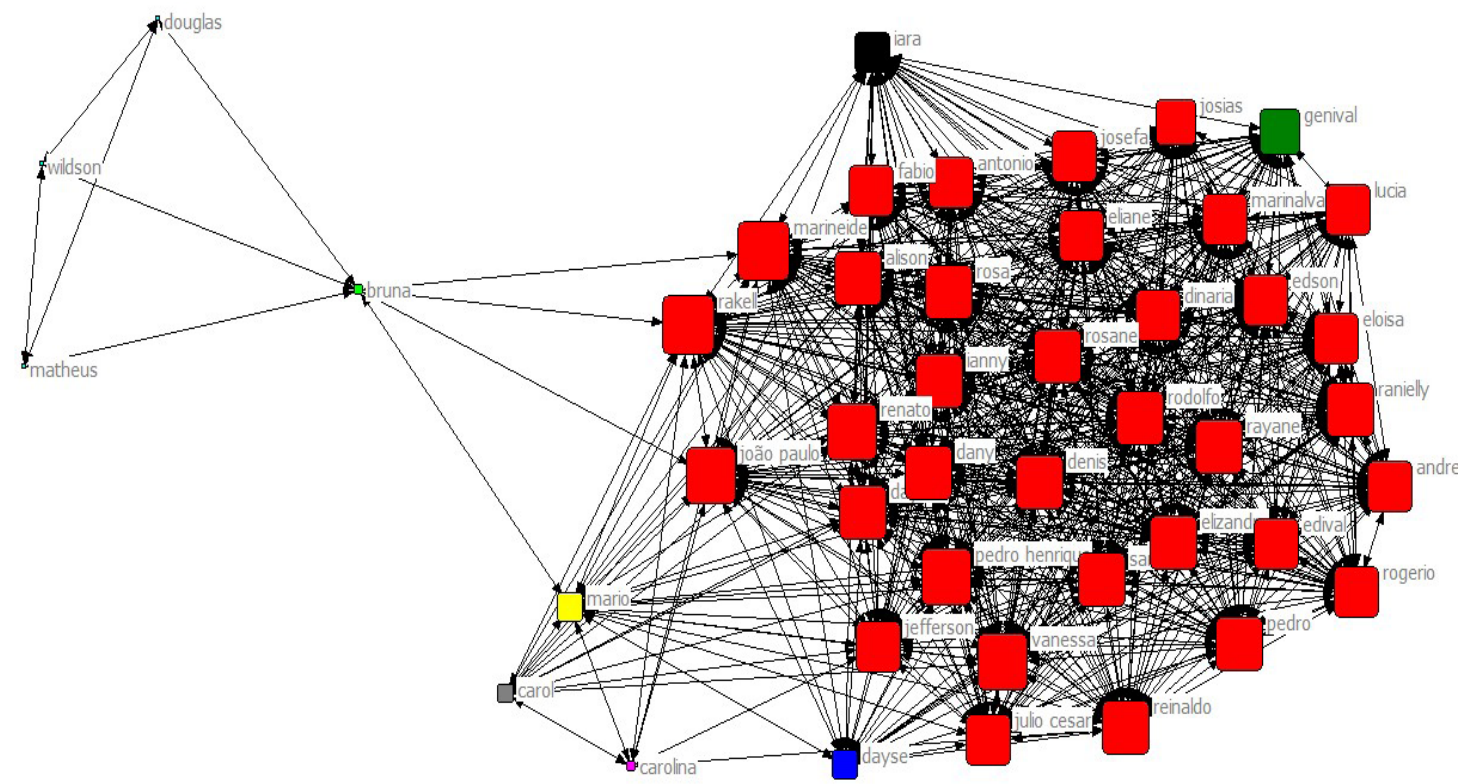

Figura 1: Representação sociométrica de uma rede pessoal de alta densidade. Nota: Elaboração própria com base em dados da CAPES (2015).

A partir da observação dessa rede pessoal, é possível constatar que existe um grupo de indivíduos que está organizado de forma mais coesa. Estes indivíduos apresentam os maiores graus de centralidade quando comparados com os outros nós dessa estrutura reticular. Esse grupo, cuja representação é feita na cor vermelha é composto predominantemente por familiares (pai, mãe, tio, primo, avô, avó) e por alguns amigos. Essa evidência empírica reforça a ideia de que o processo de socialização dos indivíduos se dá em função da sua convivência em diferentes tipos de grupos, e uma das principais é a família (Morrish, 1975). Apesar de possuir uma rede de densidade elevada, esse aluno não obteve sucesso em Português e nem em Matemática. O que poderia explicar tal fato?

Acredita-se que esse baixo desempenho em Portugês e Matemática está associado às influências recebidas no âmbito da convivência familiar. Diante disso, e considerando a forte conectividade dessa rede com o ambiente falimiar, pressupoe-se que as informações compartilhadas, na relação com os parentes não têm contribuido para potencializar o crescimento educacional deste aluno.

É importante destacar que o entendimento dessa relação entre redes e desempenho escolar envolve outras variáveis, como por exemplo, as notas de Matemática. Nesse sentido, identificou-se que os alunos com redes com moderado número de cliques tendem a ter menos chances de aprovação em Matemática, frente aos alunos que têm redes com baixo número 
de cliques. Conclui-se que redes muito clusterizadas e divididas em muitos cliques podem comprometer a obtenção de notas altas por parte do aluno.

Uma das hipóteses que pode explicar esse aspecto é o fato de existir cliques que não se conectam, o que dificulta o processo de transmissão da informação no contexto da rede. Gera, consequentemente, uma estrutura reticular de natureza desconectada (Rosa et al., 2012). Isso significa dizer que a influência negativa desses cliques sobre as notas de Matemática pode ser explicada pelo fato de haver grupos que não interagem e não compartilham informações referentes aos assuntos dessa disciplina.

Tendo em vista o grau de complexidade do conteúdo de Matemática, e a prória fragilidade no aprendizado dos alunos em relação aos fundamentos básicos de tal componente curricular, nem todos conseguem de forma ampla apresentar o domínio pleno das operações estudadas. Com isso há uma tendência dos alunos se articularem em grupos para estudarem, uma vez que um dos componentes do grupo acaba dominando mais do que os outros o conteúdo da disciplina. Esse clique fecha-se entre si, estabelecendo uma relação vertical de transmissão do conhecimento, o qual fica quase sempre restrito aos seus membros, impossibilitando assim, a socialização desse aprendizado com os outros alunos que não fazem parte do clique. Nesse caso, o clique tende a se fechar e compartlilhar somente entre si as informações por eles estudadas, por se tratarem de um conteúdo de um maior grau de complexidade, ou seja, de maior valor educacional.

Além disso, é importante salientar também que a formação de grupos pode ser motivada por diversos aspectos. Nesse caso, um clique formado por colegas de classe não necessariamente irá tratar exclusivamente de assuntos ligados às disciplinas, podendo existir outras questões mais fortes que levem à formação do clique (Piletti, 1986).

A Figura 2 pode exemplificar melhor essa questão, na qual apresenta um tipo de diagrama de clusterização da rede pessoal de um aluno em questão. Esse tipo de representação dos dados possui o propósito de expor o maior número de cliques (grupos) presentes na rede pessoal do aluno naquele momento no tempo, o que pode nos dar indícios do comportamento do seu campo relacional. Nesse caso, tem-se o total de 252 (duzentos e cinquenta e dois) cliques.

No diagrama expresso na figura 2, há na coluna alinhada a esquerda os alunos investigados, e logo a frente de cada nome, a quantidade de cliques que o aluno pertence. $\mathrm{O}$ clique tem o formato de uma letra " $\mathrm{V}$ ", e isso mostra que cada clique tem no mínimo três pessoas, como também existem cliques com uma quantidade maior do que três pessoas, os quais apresentam uma extensão maior. Há casos, onde um clique já dá origem a um outro, e assim sucessivamente, estabelecendo uma rede de ramificação e articulação entre grupos. Há, dessa maneira, a formação de uma rede via sobreposição de relações, onde vários cliques se conectam através da articulação estabelecida por um de seus atores componentes. Percebe-se que essa ramificação é feita somente através de um dos indivíduos componentes do clique, como também é perceptível a existência de grupo isolados, que não se articulam. 
doi: http://doi.org/10.15359/ree.24-1.7

URL: http://www.una.ac.cr/educare

CORREO: educare@una.cr

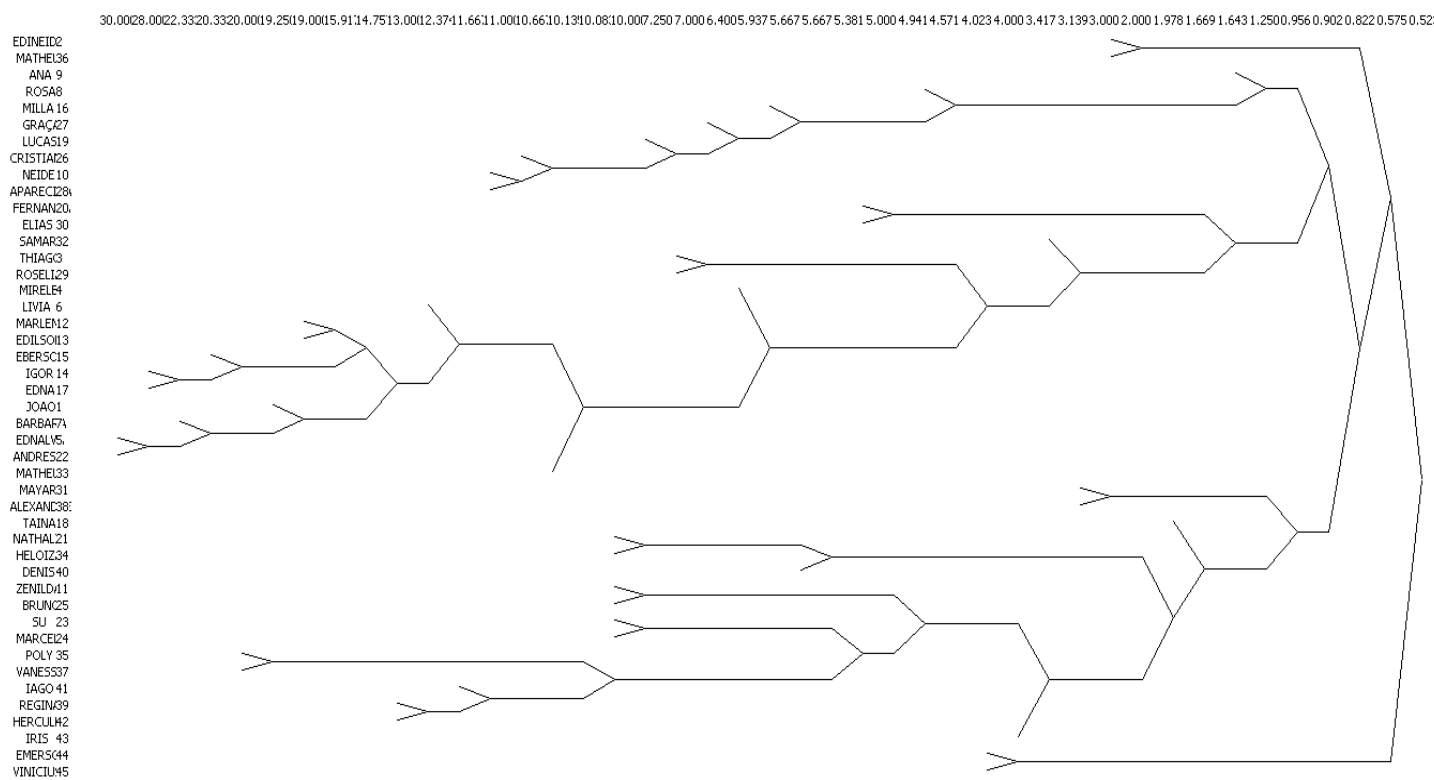

Figura 2: Diagrama de clusterização da rede pessoal de um aluno da 3a Série do Ensino Médio da Escola Estadual Santos Dumont.

Nota: Elaboração própria com base em dados da CAPES (2015).

Uma das premissas carcterizadoras desse tipo de grupo é de que a informação circula rapidamente dentro do próprio clique, o que reforça a coesão grupal e o compartilhamento de atitudes, comportamentos e ações pelos atores participantes (Rapold, 2010). Por outro lado, quando se identifica a existência de vazios no diagrma, como pode ser identificado na figura 2 , tratam-se de alunos que não fazem parte de nenhum grupo, indivíduos que não se articulam em cliques, ou seja, pessoas cuja socialização e interação não contribuem para o fortalecimento da coesão grupal de nenhum dos cliques existentes na população estudada.

Com relação ao número de participantes nesses cliques, percebe-se que em sua estrutura topológica há grupos de diferentes tamanhos. Considerando o ponto de corte mínimo de três atores articulados para a carcterização desse tipo de grupo, na representação do diagrama é possível constatar a existência de cliques com mais de três atores. Em termos estruturais, esses cliques estão distribuídos predominantemente em três ramificações: a primeira é composta predominantemente por cliques de três atores; a segunda é a maior de todas e possui principalmente grupos com mais de três atores (entre seis e nove atores); e a terceira apresenta em sua maioria cliques que possuem seis ou sete atores. 
Segundo Lino e Gomide (2012), quando a rede é impregnada de cliques com diferentes tamanhos e diferentes graus de conectividade, forma-se uma estrutura relacional hierárquica que pode não garantir a continuidade plena do fluxo informacional dentro da rede. Isso pode ser usado como argumento para explicar o fato desse indivíduo analisado, cuja rede apresenta 252 (duzentos e cinquenta e dois) cliques no total, não ter obtido sucesso nas disciplinas de Português e Matemática. Assim, ao se analisar os cliques de uma rede é interessante levar em consideração não só o aspecto quantitativo, mas também o qualitativo. Ou seja, é necessário estudar o tipo de informação que circula por entre esses grupos e de que forma ela interfere no modo de agir de determinado indivíduo.

Outra questão a ser destacada é em relação ao fato de um mesmo aluno participar de mais de um clique, ou seja, participa de vários grupos relacionais ao mesmo tempo. Alunos que apresentam essa característica, tendem a apresentar uma posição privilegiada na estrutura topológica das relações pessoais no âmbito de uma turma. Esse aluno passa a ter acesso as informações circulantes nos mais diferentes grupos, o que pode lhe possibilitar, em tese, maior poder de influência e de conhecimento sobre os diversos assuntos circulantes nas diferentes redes pessoais.

Diante do que foi exposto, das variáveis explicativas inseridas no modelo de regressão logística ambas exerceram relação negativa com a variável resposta. $O$ indidcador densidade apresentou significância, quando a variável resposta foi Português, ou seja, alunos com rede de densidade moderada apresentaram baixo rendimento em Português; Já o indicador número de número de cliques apresentou significância quando associado as notas de Matemática, pois quanto maior for o número de cliques, menor tende a ser a transmissão e o compartilhamento do conteúdo dessa disciplina entre os alunos.

Constatou-se nesses resultados que os cliques, assim como a densidade, podem ser utilizados nas pesquisas educacionais, podendo ser associados a indicadores de desempenho escolar de modo a proporcionar uma interpretação mais ampla acerca do rendimento dos alunos em sala de aula. Trata-se de uma forma de tentar captar as influências do campo relacional sobre as avaliações a que são submetidos os alunos.

Isso não significa dizer que todas as pesquisas que seguirem esses padrões terão resultados similares a esses, em todos os casos. É preciso considerar a variabilidade que há nos contextos escolares, em relação ao perfil dos alunos, os indicadores de redes usados, os parâmetros de rendimento escolar utilizados, bem como os modelos estatísticos que podem ser esolhidos para análise multivariada.

\section{Considerações finais}

Tendo em vista o objetivo estabelecido de analisar a relação entre as redes pessoais e o desempenho escolar dos alunos, dos alunos da 3a Série do Ensino Médio da Escola Estadual 
doi: http://doi.org/10.15359/ree.24-1.7

URL: http://www.una.ac.cr/educare

CORREO: educare@una.cr

Santos, localizada em Parnamirim/RN, foi possível estabelecer pontes analíticas entre o campo relacional dos discentes e o rendimento deles nas disciplinas de Português e Matemática. No decorrer dessa análise, a investigação realizada abrangeu questões relativas as redes pessoais dos alunos e os seus respectivos desempenhos no que tange ao rendimento escolar ao final do ano letivo.

Dentre as contribuições alcançadas, pode-se constatar a aplicabilidade dos conceitos e indicadores de redes pessoais no campo educacional. Nesse caso específico, os indicadores densidade e número de cliques foram devidamente utilizados para analisar a estrutura relacional dos alunos, em termos de relações estabelecidas e de segmentação de grupos. Ficou evidenciado que a questão das redes apresentou nessa discussão como sendo um recursos teórico-metodológico e analítico para se estudar questões educacionais, como por exemplo, o desempenho escolar.

Porém, a teia relacional de um aluno, caracterizada e empiricizada através dos indicadores de redes, apresentou mais consistência analítica quando associada a informações do rendimento escolar do aluno. Diante disso, foi constatado que essa rede pessoal, pode de certa forma, influenciar no que diz respeito ao rendimento do aluno em determiandas disciplinas, como foi o caso de Português e de Matemática.

No caso da Escola Estadual Santos Dumont, por exemplo, ficou constatado que alunos detentores de redes pessoais muito densas tendem a tirar notas baixas na disciplina de Português. Da mesma forma, quando os cliques foram analisados, percebeu-se um comportamento parecido, pois ficou evidenciado que alunos que possuíam redes pessoais segmentadas e divididas em grupos apresentavam tendência para notas baixas na disciplina de Matemática.

Tal cenário foi identificado para a Escola estadual Santos Dumont, considerando como variáveis explicativas a densidade e o número de cliques, e como variáveis respostas, as notas de Portugês e de Matemática, modeladas através de uma regressão logística. Esse modelo de análise construído pode ser replicado em outra escola, considerando os mesmos parâmetros usados, bem como pode ser testado por meio de indicadores diferentes, para que o modelo possa ser aprimorado e testado. Nesse processo, novas variáveis podem ser incluidas no modelo existente, como forma de se alcançar um melhor ajuste, visando modelar da melhor maneira possível a relação entre redes pessoais e desempenho escolar.

Sendo assim, tais pesquisas abrem espaço para os estudos sobre redes no campo educacional, podendo as informações relacionais servirem como elemento explicativo para interpretação dos indicadores nacionais que medem a qualidade do Ensino Básico no Brasil. Para que isso venha acontecer de fato, é necessário que haja uma aproximação entre várias áreas do saber, tais como a Sociologia, a Pedagogia e a Estatística, no intuito de se alcançar todas as nuances que envolvem essas pesquisas, do ponto de vista teórico, metodológico e analítico. 
Além disso, sugere-se o uso desses estudos não só nas pesquisas de órgãos oficiais responsáveis pelo planejamento educacional nacional, como também no âmbito das escolas, como forma dos gestores terem mais ferramentas para traçarem o planejamento pedagógico, com ênfase no perfil relacional de cada aluno.

\section{Referências}

Berten, A. (2007). A epistemologia holista-individualista e o republicanismo liberal de Philip Pettit. Kriterion. Revista de Filosofía, 48(115), 9-31. doi: https://doi.org/10.1590/S0100$\underline{512 \times 2007000100002}$

Borges, C. C. \& Magalhães, A. S. (2011). Laços intergeracionais no contexto contemporâneo. Estudos de Psicologia, 16(2), 171-177. Recuperado de https://doi.org/10.1590/S1413$\underline{294 \times 2011000200008}$

Bortoni-Ricardo, S. M. (2005). Nós cheguemu na escola, e agora? Sociolinguística na sala de aula. São Paulo: Parábola.

Bourdieu, P. (2001). Meditações pascalianas (Trad. S. Miceli). Rio de Janeiro: Bertrand Brasil.

Coordenação de Aperfeiçoamento de Pessoal de Nível Superior (CAPES). (2015). Projeto: O Habitus de Estudar: Construtor de uma nova realidade da educação básica da Região Metropolitana de Natal.

Carvalho, J. M. (2013). Produção cultural e redes de sociabilidade no currículo e no cotidiano escolar. Revista Brasileira de Educação, 18(53), 399-414. doi: https://doi.org/10.1590/S1413$\underline{24782013000200009}$

Castells, M. (1999). A sociedade em rede (Trad. R. de Venancio Majer). São Paulo: Paz e Terra.

de Azevedo, T. B. \& Rodriguez, M. V. R. Y. (Agosto, 2010). Softwares para análise de redes sociais ARS. Anais do VI Congresso Nacional de Excelência em Gestão: Energia, Inovação, Tecnologia e Complexidade para a Gestão Sustentável. Niterói, RJ, Brazil.

Degenne, A. \& Forsé, M. (1999). Introducing social networks. London: SAGE. doi: https://doi. org/10.4135/9781849209373

Gadotti, M. (2005). A questão da educação formal/não-formal. Sion: Institut Internacional des Droits de L'enfant. Recuperado de https://docplayer.com.br/5445484-A-questao-daeducacao-formal-nao-formal.html

Hanneman, R. A. (2001). Introducción a los métodos del análisis de redes sociales (Capítulo 8, Trad. F. de la Rúa). USA: Departmento de Sociología de la Universidad de California, Riverside. 
doi: http://doi.org/10.15359/ree.24-1.7

URL: http://www.una.ac.cr/educare

CORREO: educare@una.cr

Lemos, M. R. (2010-2011). Sociabilidade em destaque: Um ensaio teórico a partir do intercâmbio analítico entre Ferdinand Tönnies e Émile Durkheim. Cadernos de Campo, 14 e 15, 127-139. Recuperado de https://periodicos.fclar.unesp.br/cadernos/article/view/5166/4231

Levi-Strauss, C. (1980). A noção de estrutura em etnologia; raça e história; totemismo hoje. São Paulo: Abril cultural.

Lino, C. R. G. \& Gomide, M. (2012). Análise de redes sociais na avaliação do programa de controle de hanseníase em um município do interior do Brasil. Caderno de Saúde Coletiva, 20(1), 32-40.

Lisboa, A. V., Féres-Carneiro, T. \& Jablonski, B. (2007). Transmissão intergeracional da cultura: Um estudo sobre uma família mineira. Psicologia em Estudo, 12(1), 51-59. doi: https://doi. org/10.1590/S1413-73722007000100007

Luhmann, N. (1995). Social systems. California: Stanford University Press.

Martinez-Otero, V. (2012). Teoria e prática da educação. Natal: EDUFRN.

Meksenas, P. (2002). Pesquisa social e ação pedagógica: Conceitos, métodos e práticas. São Paulo: Loyola.

Morrish, I. (1975). Sociologia da educação: Uma introdução. Rio de Janeiro: Zahar.

Piletti, N. (1986). Sociologia da educação. São Paulo: Ática Editora.

Rapold, I. M. (2010). Estabilidade X mudança nas organizações: Uma análise da dinâmica das redes sociais informais de confiança (Dissertação mestrado). Universidade Federal da Bahia. Recuperado de https://pospsi.ufba.br/sites/pospsi.ufba.br/files/ingrid rapold.pdf

Riani, J. L. R. (Setembro, 2004). Impacto dos fatores familiares, escolares e comunitários na probabilidade de cursar a escola na idade adequada no ensino fundamental e médio. Traqbalho apresentado no XIV Encontro Nacional de Estudos Populacionais, Caxambú-MG.

Rigotti, J. I. R. \& Cerqueira, C. A. (2004). As bases de dados do INEP e os indicadores educacionais: Conceitos e aplicações. Em Rios-Neto, E. L. G. \& Riani, J. L. R. (Org.), Introdução à demografia da educação (pp. 73-87). Campinas: Associação Brasileira de Estudos Populacionais (ABEP). Recuperado de http://www.abep.org.br/publicacoes/index.php/livros/article/view/152/150

Rosa, M. G., Fadigas, I. S., Andrade, M. T.T. \& Pereira, H. B. B. (julho, 2012). Abordagem de redes por cliques: Aplicação a redes de coautoria. Em Brazilian Workshop on Social Network Analysis and Mining, XXXII Congress olf the Brazilian Compuer Society Computer Society. Curitiba. Recuperado de http://www.lbd.dcc.ufmg.br/colecoes/brasnam/2012/0026.pdf 
Soares, I. O. (1995). A comunicação no espaço educativo: Possibilidades e limites de um novo campo profissional. Perspectiva, 13(24), 11-22. Recuperado de https://periodicos.ufsc.br/ index.php/perspectiva/article/view/10702/10206

Soares, W. (2002). Da metáfora à substância: Redes sociais, redes migratórias e migração nacional e internacional em Valadares e Ipatinga (Tese Doutorado). Universidade Federal de Minas Gerais, Belo Horizonte. Recuperado de http://www.bibliotecadigital.ufmg.br/dspace/ bitstream/handle/1843/FACE-5NGJ5E/tese weber soares.pdf?sequence=2

Sprinthall, N. A. \& Sprinthall, R. C. (1997). Psicologia educacional: Uma abordagem desenvolvimentista. Lisboa: McGraw-Hill.

Tomaél, M. I. \& Marteleto, R. M. (2013). Redes sociais de dois modos: Aspectos conceituais. TransInformação, 25(3), 245-253. doi: https://doi.org/10.1590/\$0103-37862013000300007

Tönnies, F. (1887). Comunidad y sociedad. Barbari y civilización en la filosofia social. Buenos Aires: Editorial Lousada.

Velázquez, O. A. \& Aguilar, N. (2005). Manual introductorio al análisis de redes sociales: Medidas de centralidad. Ejemplos prácticos con UCINET 6.85 y NETDRAW 1.48. México:UAEM. Recuperado de https://docplayer.es/934089-Manual-introductorio-al-analisis-de-redes-sociales.html

Wasserman, S. \& Faust, K. (1996). Social network analysis: Methods and applications. New York: Cambridge University Press.

Watts, D. J. (2009). Seis graus de separação: A evolução da ciência de redes em uma era conectada. São Paulo: Leopardo. 